DOI: $10.17805 / z p u .2016 .2 .8$

\title{
Биосоциальный человек и возможные направления антропосоциальной эволюции
}

\author{
E. А. ТУРИНЦЕВА, Е. В. РЕШЕТНИКОВА \\ (ИРКУТСКИЙ ГОСУДАРСТВЕННЫЙ УНИВЕРСИТЕТ)
}

В статье обсуждается биосоциальная сущность человека и связанные с ней перспективы развития человечества. Предмет статьи рассматривается с точки зрения концепции биосоциологии, предложенной Вал. А. Луковым, - с позиций междисциплинарности, встречного дрейфа естественных и гуманитарных наук, как новое теоретизирование на тему соотношения биологического и социального в человеке.

Исследование выявило, что если определять социальное и личностное как развитие универсальных для царства животных биологических стратегий, то содержательным отличием эволюции человека от эволюции других животных, имевших на вооружении те же стратегии, явилось параллельное и равновесное развитие биоиндивидуального организма (личности) и социальности (общества). Сегодня направления антропосоциальной эволюции могут быть связаны с возможными перекосами в сторону превалирования развития личности или в сторону общественного императива, одинаково приводящих к уничтожению человека как такового и катастрофе человечества. В случае же сохранения равновесия человечество может успешно развиваться.

Если же понимать социальное как «небиологическое», то в этом случае можно подойти к проблеме биосоциального человека с позиций разграничения естественного и искусственного и связать социальное прежде всего с орудийной деятельностью человека, развитием техники и технократической цивилизации. Сегодня симбиоз человека и техники вполне способен создать принципиально новое тело, причем проще и выгодней создать небиологическое тело из нанокомпозитных материалов, лишенное многих «человеческих», организменных функций и обусловленных ими систем. Таким образом, в будущем человек частично или полностью будет лишен конституирующего человека биологического тела. Возникает также вопрос относительно оснований для обществообразующего взаимодействия «новых людей» - киборгов. Авторы рассматривают несколько вариантов и приходят к выводу о неизбежности создания «культивируемого» общества у киборгов. В этой связи в рассуждениях с точки зрения определения биосоциального человека как соотношения естественного и искусственного авторы предполагают постепенный и полный переход от естественного к искусственному миру, в конечном счете без человека и его социальности.

Ключевые слова: биосоциология, антропосоциальная эволюция, развитие человека, гуманизм, трансгуманизм 
ВВЕАЕНИЕ

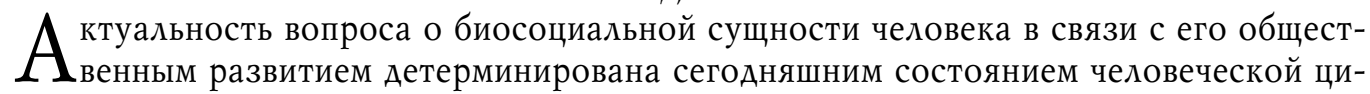
вилизации, поиском путей совершенствования человека и общества, альтернативных тем, что были апробированы в XX в. и зашли в определенного рода тупик. Исследование биосоциальной сущности человека с учетом научного багажа предыдущих поколений ученых и философов, а также новейших разработок, на наш взгляд, способно пролить свет на те направления движения человечества в целом, которые в настоящее время требуют сделать наш выбор.

Прошло время, когда человечество могло довериться природным эволюционноэкологическим механизмам и «плыть по течению». Сегодня мы имеем все возможности и обязанность сделать сознательный выбор, корректировать наше развитие на основе знаний, морали и ответственности как перед человечеством, так и перед природой, миром, вселенной. В этом и заключается основная проблема - не впадая в крайности сверхоптимистического взгляда на перспективы Человека, но и не подчиняясь пессимистическим прогнозам, наблюдая за миром природы и точно зная место в нем Человека, составить такую «дорожную карту» общественного развития, которая могла бы быть в действительности реализована и приводила бы к оптимальному результату. Большую трудность в нашем общем движении к достижению оптимального результата развития человека и общества, как мы полагаем, составляет отсутствие активного конструирования моделей желаемого будущего общества, слабое осознание цели общего развития как на уровне повседневности, так и в научных исследованиях.

Цель данной статьи - проанализировать биосоциальную сущность человека, с тем чтобы сопоставить ее с рядом гипотез о дальнейших направлениях антропосоциальной эволюции. Предмет статьи рассматривается с точки зрения концепции биосоциологии, предложенной Вал. А. Ауковым, - с позиций междисциплинарности, встречного дрейфа естественных и гуманитарных наук, как новое теоретизирование на тему соотношения биологического и социального в человеке. В некотором смысле в данной статье мы делаем шаг в сторону разрешения противоречия между сегодняшним состоянием человечества и его желаемым состоянием.

\section{ПРЕАПОСЫИКИ И ПЕРСПЕКТИВЫ ПРИМЕНЕНИЯ БИОСОЦИОАОГИЧЕСКОГО ПОАХОАА В ИССАЕАОВАНИЯХ АИНАМИКИ \\ ЧЕАОВЕКА И ОБЩЕСТВА}

На сегодняшний день в исследовании вопросов происхождения и развития человека и общества, как известно, сложилось несколько направлений, в том числе теологического, космологического и фантастического характеров. Что касается аргументированных научных направлений, то начиная с XIX в. постепенно формируются два основных вектора познания антропосоциогенеза. Один из них, натуралистический, представленный теориями, относящимися к биологической редукции социальных явлений и процессов, а также теориями, фиксирующими внимание на антропосоциогенезе как части единого процесса эволюции природы, провозглашал тождество человека и других живых существ. Он был сформирован на волне популярности теории Ч. Аарвина и в целом успеха естественных наук. Аругой, назовем его позитивистским, был вызван к жизни бурным развитием точных наук и техники, а также становлением специфических социальных отношений, свойственных капиталистической системе 
производства. Он предполагал прогресс человека и поступательное однонаправленное развитие человечества к вершинам управления миром природы, при условии ее покорения и полного подчинения, с необходимостью отделяя человека от природы и помещая над ней.

О бесперспективности того и другого отдельно взятых направлений в отношении изучения общества писал в 1908 г. Е. В. Ае Роберти, утверждая, что сформировавшиеся на тот момент «теории, отождествляющие социальные явления с их органическими корнями или предпосылками... также теории, отождествляющие их (социальные явления. - E. T., E. Р.), наоборот с их психологическим расцветом, т. е. с вытекающими из них последствиями» (Ае Роберти, 2008: 223), не правы, так как «если бы авторы этих теорий были правы, то не было бы нужды какой-либо автономной социологии, а надо было бы только или расширить пределы биологии, дав в них место, в особой главе, изучению человеческих союзов (агрегаций и конгрегаций), или соответственно увеличить компетенцию психологии, включив в нее все коллективные проявления духа» (там же).

Однако позже разногласия между двумя подходами усилились, особенно в связи с тенденцией к дифференциации наук и поиску тех точных определений объекта и предмета конкретной науки, которые бы однозначно выделяли ее среди других. В результате в конце XX в. исследования человека и общества оказываются в пограничной ситуации между биологией, чьи попытки изучить в человеке что-то еще, кроме физиологии и анатомии его тела, признаются неправомерными, и гуманитарными науками, пытающимися всеми способами вычленить человека и общество из единой системы живой природы, ставя его над природой и приписывая ему управляющие функции.

Указанные направления, соперничая и совершенствуя свои подходы и методы, подошли к окончанию XX в., так и не решив детерминированный их соперничеством основной вопрос о соотношении биологического и социального в человеке и поставив за скобки вопрос о соотношении биологического и социального в обществе, так как побеждавший в первой половине века позитивистский вектор рассматривает общество как явление чисто социальное, человеческое, т. е. надорганическое или небиологическое.

Вместе с тем оптимизм в отношении вопросов прогрессивного развития человека и общества сменился скептицизмом и апокалиптическими сценариями, а вместо энтузиазма покорения природы появилось ощущение смертельной угрозы экологического кризиса. В тот же момент экзистенциалисты фиксируют переход человека и общества от состояния радости борьбы и свершений к состоянию отупения от пронизывающей повседневности, отказа от поисков смысла бытия, а следовательно, и отказа от осмысленного, человеческого существования. В этих условиях, с одной стороны, биологические науки все настойчивей стучатся в приоткрытые двери наук гуманитарных, отбрасывая вульгарные формы бихевиоризма и социобиологии и предлагая новый синтез знаний о природе и обществе в рамках этологии, экологии, этнологии и других наук. С другой стороны, гуманитарные науки постепенно приходят к выводу, что человеку не удалось пока «выйти из природы и громко хлопнуть за собой дверью», биологическое в человеке еще сильно и, более того, структуры общества, социальные процессы и явления не могут быть осознаны без обращения к их биологическим корням. Возникновение новых научных направлений - биофилософии, биосоциологии, социоестественной истории и др. - подтверждает эту тенденцию. Происходит воз- 
вращение к дискуссии XIX в., только вместо позитивизма мы скорее имеем дело с негативизмом, направлением, утверждающим регресс человечества, детерминированный теми же факторами, что и ранее провозглашаемый прогресс, - развитием точных наук и техники, а также развитием специфических социальных отношений, свойственных капиталистической системе производства в ее завершающей, с точки зрения некоторых ученых, стадии (см.: Фурсов, 2010).

Нереализованный позитивистский вектор и ощущаемый кризис в развитии человечества требуют осмысления происходящего и поиска путей выхода.

Одним из таких путей мы считаем развитие гуманистических идей и принципов в теории и практике (Решетников, 2012; Решетникова, 2005, 2012; Решетникова, Туринцева, 2013; Туринцева, Решетникова, Гладкова, 2015). Среди предлагаемых сегодня направлений есть и обращение к натуралистическому вектору исследований развития человека и общества, только на новом уровне и с высоты теоретических достижений естественных и гуманитарных наук XXI в. Это, прежде всего, биосоциология, представляющая собой, по определению Вал. А. Аукова (Ауков, 2011, 2012abcd, 2013ab, 2014, 2015), формирующуюся научную концепцию междисциплинарного характера и практику исследования сложных по природе явлений современной общественной жизни, исходящих из неразрывной связи биологического и социального компонентов в жизни человека и человеческих сообществ (социальных общностей). В настоящем биосоциология позиционируется как новая вариация теоретизирования на тему баланса в человеке биологического и социального (Ауков, 2011, 2013a, 2014, 2015). Направленность биосоциологии в будущее отражена ее задачами. Вал. А. Ауков пишет: «...биосоциология имеет своей важнейшей задачей выявить возможные трансформации общества через накопление в новых поколениях критической массы биологических и интеллектуальных (под воздействием факторов внешней среды обитания и вызванных искусственными средствами), а также социокультурных изменений» (Иуков, 2014: 275). Аобавим: выявить для того, чтобы предупредить катастрофические последствия неверно принятых решений, чтобы защитить человечество от него самого, способствовать его сохранению и процветанию. Таким образом, становится актуальным новый, биосоциологический и, одновременно, гуманистический, взгляд на человека и общество, который позволяет сделать выводы не только относительно прошлого человечества, но и относительно его ближайшего и отдаленного будущего, дать ориентиры для сохранения и развития цивилизации.

\section{БИОСОЦИААЬНЫЙ ЧЕАОВЕК КАК СООТНОШЕНИЕ АИЧНОСТИ И ОБЩЕСТВА В ПРОГНОЗЕ АНТРОПОСОЦИААЬНОГО РАЗВИТИЯ}

В наши дни аксиомой становится понимание человека как существа биосоциального. Однако «биологическое» и «социальное» в нем продолжает сравниваться и «взвешиваться на точных весах». При этом особенно трудной кажется задача выделения и описания «социального», которое обычно позиционируется как присущее только человеку, отличающее его от животных, нечто «надбиологическое»или противоположное биологическому.

Представляется возможным посмотреть иначе на данную проблему, обратившись к наследию Ае Роберти. В работе «Задачи социологии» он рассматривает социологию как науку, основанную на биологии и предшествующую психологии, а социальные явления - как специфические изменения (осложнения) явлений биологических (Ае Роберти, 2008: 223). Автор утверждает, что любые социальные явления являются 
биосоциальными, а любые высшие проявления их - психологические явления становятся по определению биосоциопсихологическими. Таким образом, личностное (психологическое) и социальное (общественное) одинаково коренятся в биологическом основании, однако по отношению друг к другу наблюдается первичность социального и вторичность личностного (психологического). Аалее он пишет о том, что, внимательно присмотревшись к животным, например к пчелам или муравьям, мы видим крайнюю степень развития социальности при недостаточном развитии индивидуального организма - его интеллекта и личности, его «психофизической энергии». В другом случае, при сильной «психофизической организации» индивидуального организма, почти не отличающейся от таковой у человека, мы видим «слабую, едва намеченную общественность» (там же: 225). Результат, с точки зрения Е. В. Ае Роберти, один и тот же - новые социопсихофизиологические явления не формируются, нет системы их сознательной передачи от поколения к поколению. Аействительно, как показали в дальнейшем исследования этологов, пчелы, например, имеют минимальную степень индивидуальности, они полностью подчинены инстинктивным программам, определяющим их общественное поведение вплоть до того, что совокупности особей, выполняющих одну и ту же функцию, могут быть сравнимы с функциональными тканями целостного организма. Так же как по многочисленным опытам с обезьянами, имеющим целью обучить их человеческим коммуникациям, очевидно, что даже самые умные из них не становятся людьми. При этом әтологами были отмечены и такие явления в поведении животных, которые, по мнению Вяч. Вс. Иванова, являются зачатками культуры. Так, было обнаружено, что у необщественных ос структура ячейки и ее материал служат для хранения информации, что может служить примером построения искусственных запоминающих устройств, используемых для общения между поколениями, которые непосредственно между собой не общаются. Вяч. Вс. Иванов пишет: «В систему передачи информации у необщественной осы при этом встроено будущее, что можно сопоставить со всеми человеческими системами передачи культурной информации» (Иванов, 2007: 36). Вместе с тем данная передача информации общественно-функциональна, в ней нет никакой индивидуализации, она нужна только для того, чтобы личинка осы смогла питаться и самостоятельно выбраться из ячейки, это инструкция, а не художественное произведение. Это различие делает общий Аля человека и животных способ передачи информации в одном случае животным, в другом - человеческим.

Таким образом, многие стратегии человека и животных аналогичны, и развитие социальности и личности - это универсальный эволюционный путь, по которому пошли многие животные, но только Homo sapiens стал тем единственным и уникальным природным видом, в котором развитие социальности и развитие личности оказались гармонично сбалансированы в ходе эволюции, что и привело, на наш взгляд, к возникновению собственно человека, его культуры, как коллективного сознательного и бессознательного опыта, передающегося специальными, присущими только человеку, средствами, и его цивилизации, понимаемой как постоянное совершенствование функциональных и вынесенных за пределы тела орудий, преобразующее пространство.

Однако эта же логика приводит к выводу о том, что личностное не может проистекать из социального (общественного), как невозможно и обратное. Социальное и личностное развитие должно происходить одновременно и параллельно, и в том случае, когда данный параллелизм по каким-то причинам нарушается, исчезает человек, а на 
его месте возникают пчелы с их гиперсоциальностью или обезьяны, чья социальная организация отстает от индивидуальных интеллектуальных и психических способностей отдельных особей.

Суть человека и его специфику, таким образом, составляет такое эволюционное развитие, в котором существует параллельный рост личности и социальности, уравновешенный и неразрывный антропосоциогенез. Человеческое социальное можно определить как равновесное психосоциальное, сформированное в ходе биологической эволюции и продолжающееся в русле развития биосферы, где динамическое равновесие между психологическим (личностным) и социальным (общественным) устанавливается в непрерывном взаимодействии совершенствующегося индивидуального человека и совершенствующегося общества. Будущее антропосоциальной эволюции с этой точки зрения зависит от сохранения равновесия и параллельного, коэволюционного развития человека и общества. А. Маслоу в книге «Аальние пределы человеческой психики» так определяет это направление антропосоциальной эволюции: «Проблему создания хорошего человека можно с уверенностью назвать проблемой самоэволюции человека. Нам необходим такой человек, который был бы ответствен за себя и свое развитие, досконально знал самого себя, умел осознавать себя и свои поступки, стремился к полной актуализации своего потенциала и т. А. Столь же важной и насущной, как и вышеназванная, является проблема создания хорошего общества» (Маслоу, 1999: 32).

«Хорошего» человека и «хорошее» общество Маслоу считает залогом гармоничного развития человечества. Но попытка реализовать подобную идею была сделана, например, в XX в. в рамках социалистической системы и закончилась она неудачей. Почему? С точки зрения обсуждаемых проблем представляется, что ошибка советской власти заключалась именно в нарушении баланса между развитием личности и развитием общества. Метафорически советское общество стало «обществом пчел», в котором коллективные интересы настолько выше личных, что последние были сведены почти к нулю. В то же время западное общество делает ту же самую ошибку, только обратную - индивидуальные личные интересы, права и свободы превалируют над коллективными, общественными, в результате чего человек как таковой исчезает, остается самодоводьное животное - обезьяна в своей повседневности и стадной локальности. Парадокс заключается в том, что советская система, провозглашавшая творческое развитие каждой личности и действительно очень много предпринявшая для этого, экономически была устроена как распределительная, уравнительная система, гасившая инициативу через требование «быть как все». Такая социальная инновация, как социалистическое соревнование, хотя и способствовала решению проблемы, не могла урегулировать ее полностью. В современном западном обществе инициатива личности, ее самостоятельность поддержана всем ходом его исторического развития. При этом развитие әкономической системы по капиталистическому пути сегодня требует массовой «серости» идеального потребителя, создания тотально контролируемого общества, каждый член которого в любой точке мира, так же как все, функционирует в режиме «деньги - покупки», потребляет предлагаемый однообразный, по сути, набор товаров и услуг и остается просчитываемым и предсказуемым для маркетологов. В. Г. Федотова: пишет «В 30-е годы прошлого века, в пик перехода Запада к массовому производству, гордость Запада автономный индивид - был вытеснен массовым индивидом, усредненным продуктом неоднородной, но по-своему - в плане своего тяготения к упрощенным образ- 
цам культуры - гомогенной массы, создаваемой массовым производством» (Федотова, 2005: 14).

С этих позиций представляется очень верной известная гипотеза П. Сорокина о конвергенции, намного опередившая свое время (Sorokin, 1944).

Опыт социализма и капитализма должен быть объединен с целью получения «хорошего» человека и «хорошего» общества и в целом выживания и успешного эволюционирования человечества. Этот гуманистический сценарий, пожалуй, является единственной альтернативой той катастрофе, тень которой на сегодняшний день нависла над нами.

Итак, если конституировать социальное как универсальное для эволюции животных и человека, учитывая человеческую специфику социального, состоящую в равновесии между общественным и личностным развитием, то, очевидно, вопрос о соотношении биологического и социального в человеке в этом случае не может быть решен, поскольку биологическое и есть социальное и личностное, а социальное и личностное и есть биологическое. При этом дальнейшие направления антропосоциальной эволюции могут быть связаны с возможными перекосами в сторону превалирования развития личности или в сторону общественного императива, одинаково приводящих к уничтожению человека как такового и катастрофе человечества. Задача выживания и успешного существования человечества, таким образом, заключается в том, чтобы сохранить баланс - человека как самосовершенствующейся творческой личности и общества - как системы взаимосодействия и взаимозависимости людей.

\section{БИОСОЦИААЬНЫЙ ЧЕАОВЕК КАК СООТНОШЕНИЕ ЕСТЕСТВЕННОГО И ИСКУССТВЕННОГО В АСПЕКТЕ НАПРАВАЕНИЙ АНТРОПОСОЦИААЬНОЙ ЭВОАЮЦИИ}

Если оставаться на позиции социального как «небиологического», то можно поАойти к проблеме биосоциального человека по-другому. А именно с точки зрения разделения естественного и искусственного. Нельзя не отметить, что при всей похожести и несомненной преемственности человек все-таки разительно отличается от животных, прежде всего своей орудийной деятельностью, способностью производить искусственные, неприродные объекты.

B. С. Степин относительно этого пишет: «Аве взаимосвязанные компоненты материального существования человека (биологическое тело и “неорганическое тело Цивилизации”) образуют сложное и противоречивое целое. <...> Биологическая компонента является продуктом естественной эволюции биосферы, тогда как “неорганическое тело Цивилизации” возникает и развивается как искусственно сконструированная деятельностью человека линия әволюции природных объектов. По мере развития возникает дивергенция этих двух линий...» (Степин, 2011: 27).

Техника, здания из стекла и бетона и другие объекты материального производства человека действительно не являются биологическими, а в настоящее время и вообще природными. Самое же замечательное в плане прогноза антропосоциальной эволюции начинается тогда, когда человек принимается производить не только материальные искусственные объекты, но и материальные искусственные субъекты сначала используя для этого тело человека, заменяя детали - конечности, сердце, почки и др. на технологические и более совершенные устройства, а потом и вовсе обходясь без него, так как тело искусственного интеллекта можно бесконечно варьировать. 
Природа с помощью симбиоза - универсального механизма в эволюции живых организмов - когда-то создала и тело человека. Сегодня симбиоз человеческого тела и техники вполне способен создать принципиально новое тело - на биологической основе или на основе новых материалов, с биологическими атавизмами или без них.

Н. М. Амосов в книге «Алгоритмы разума» пишет: «"Генная инженерия" - не утопия, но возникающие здесь проблемы гораздо сложнее, чем представляем мы это сегодня. Аля целенаправленной переделки генотипа человека нужна его кибернетическая “действующая модель” огромной сложности. Это значительно труднее, чем создать искусственный интеллект. Опыт развития науки и техники показал, что люди не повторяют природу, а изобретают новые решения. Уверен, что проще сделать "нового человека", чем переделывать имеющегося» (Амосов, 1979: 193). Но будет ли этот новый человек человеком? Например, в трансгуманистическом сценарии с предполагаемым в нем индивидуальным бессмертием (Прайд, 2008: Электронный ресурс) выгоднее иметь нанотехнологическое тело без лишних для бессмертного тела функций, реализуемых у человека в системах органов пищеварения, выделения, размножения и др. Но эти «лишние» функции и обусловленные ими системы немаловажны для человека и конституируют его! Они имеют отражение в культуре, социальности, в психике и т. А. Вопрос о соотношении биологического и социального в человеке в этом случае может перейти в проблему соотношения человеческого и технологического в киборге.

Возможно, конечно, и возникновение нового общества киборгов и технических устройств с искусственным интеллектом. Начало возникновения такого общества мы наблюдаем сейчас - на наших глазах происходит глобальная перестройка «старочеловеческого» общества в информационное. Признаки перехода от человеческого к сверхчеловеческому обществу мы видим в молодежи, склонившейся над электронными гаджетами, в росте социопатий, в эпидемии аутизма и многом другом. В. С. Степин пишет по этому поводу: «Появление новых способов кодирования представляет собой не просто технические инновации. Оно закрепляет изменения характера коммуникаций и способов включения индивидов в социальные связи, а следовательно, участвует в определении тех границ, в которых варьируются те или иные формы социального поведения и деятельности» (Степин, 2011: 50). Аругими словами, техника и технологии изменяют не только тело человека, но и саму социальность, которая все более отходит от своих биологических корней и насыщается элементами, принципиально отсутствующими в любых примерах социальности животных, становясь абсолютно неприродной, искусственной, если понимать искусственное как все, созданное человеком.

Как же будет осуществляться взаимодействие между киборгами в новой искусственной социальности? И главное - зачем оно будет осуществляться, если все человеческие, атавистические к тому времени, поводы для взаимодействия, такие как репродукция, прокормление, защита от врагов и т. п., будут исчерпаны? Может ли общественное быть вообще отброшено за ненадобностью?

Учитывая тенденцию к вытеснению природного естественного мира искусственным, очевидно, что будущее взаимодействие киборгов будет основано на искусственных элементах социальности. Рассмотрим вариант экономических взаимоотношений в качестве основания для взаимодействия киборгов.

Экономическое взаимодействие по сути своей искусственно, это человеческое изобретение, хотя потенциал для него есть в мире животных, и, например, обученные 
шимпанзе очень быстро овладевают навыками денежно-ресурсного обмена. Последние исследования так называемых искусственных обществ - компьютерных моделей поведения дают понимание стратегий и тактик взаимодействий на экономической основе. Созданная Аж. Эпштейном и Р. Акстеллом «сахарная модель» (Sugarscape Model) воспроизводит поведение отдельного жука-агента, занимающегося сбором и потреблением продукта для жизнеобеспечения (сахара - в модели), который возникает по установленным правилам на территории двухмерного пространства (Epstein, Axtell, 1996). В дальнейшем модель была усовершенствована - введены два продукта (сахар и сироп), которыми жуки смогли обмениваться на определенных условиях, и, таким образом, в их обществе появилась экономика.

Если мы поставим киборгов на место жуков, потребляющих и обменивающих сахар, то возникает вопрос - какой ресурс станет для них необходимым? Что они смогут предложить для обмена? Представляется, что этот ресурс обладает следующими характеристиками: это индивидуальный ресурс (запчасти, предназначенные для поддержания тела одного киборга), поскольку бессмертный киборг не имеет потомков и целей воспроизводства; это энергетический ресурс (согласно законам термодинамики физическое бессмертие тела, производящего работу, возможно только при восполнении энергетических затрат); это однообразный ресурс, так как тело киборга отграничено от окружающей среды и поэтому малофункционально, а следовательно, не нуждается в разнообразных ресурсах для обеспечения многих функций. Последняя характеристика указывает на невозможность обмена. Образно говоря, жуку-киборгу не нужны сахар и сироп. Только - сахар. Если доступ к такому ресурсу неограничен, то, очевидно, у киборгов нет никаких причин для взаимодействия, и общество не образуется, а сами киборги становятся вариантом стратегии растений - замирают в пределах источника энергии - этакое думающее дерево... Но о чем дереву думать? В этом случае искусственный носитель интеллекта - аналог и продолжение нервной системы человека оказывается не у дел. Если же доступ к ресурсу ограничен, то у киборгов возникают конкурентные взаимоотношения, властная иерархия и стратификация общества - это напоминает людей, но только отчасти. Общество киборгов, созданное на основе конкуренции за ресурсы однонаправленно, т. е. борьба идет до тех пор, пока ресурсом не завладеет последний оставшийся киборг. Таким образом, экономическая модель взаимодействия не подходит для существования общества киборгов.

Есть другой вариант организации общества сверхлюдей. Он основан на создании и удовлетворении искусственных потребностей. требляют большое количество материальных, интеллектуальных и психологических продуктов, в которых, по сути, нет жизненной необходимости. Речь идет прежде всего о тех элементах чисто человеческого существования, которые проявляются в культуре. Аля примера попробуем сконструировать будущее потребностей в дружбе при условии, что естественные источники ее (необходимость взаимопомощи) будут преодолены. Э. Тоффлер, ссылаясь на статью К. Тола «Аружеские отношения в будущем» пишет: «...стабильность, основанная на близких отношениях с небольшим количеством людей, окажется неэффективной вследствие высокой мобильности, расширения круга интересов и различий в способности к адаптации и переменам, свойственным людям, живущим в высоко автоматизированном обществе» (Тоффлер, 2002: 124). Поэтому, как считает Э. Тоффлер, структура дружеских связей большинства людей в будущем изменится таким образом, что длительные дружеские свя- 
зи с немногими, характерные для прошлого, сменятся близкими кратковременными отношениями со многими людьми. В то же время в современном нам обществе пропагандируется идеал свободы индивидуального человека от кого бы то и от чего бы то ни было. Возникающая, таким образом, перспектива дружеских отношений между людьми ближайшего будущего - это кратковременные отношения стремящихся к полной «независимости», т. е. изоляции, субъектов. Однако полной изоляции все же не произойдет, так как у людей всегда остается биологически обусловленная потребность в общении. Но у киборгов ее нет, и в тех же условиях для киборгов вполне возможна полная изоляция. Тогда дружеские отношения для них лишаются всяких оснований.

Стоит ли говорить, что без навязанной извне идеи необходимости дружеского взаимодействия и откровенной манипуляции в обществе киборгов никакое дружеское взаимодействие происходить не будет? Это главная проблема всех создаваемых человеком искусственных систем - они не относятся к самоорганизующимся и саморегулируемым, поэтому всегда существует необходимость их поддержания и внешней регуляции, иначе говоря, общество киборгов не может не быть культивируемым (регулируемым).

Но наибольшую опасность для общества киборгов представляет грядущее индивидуальное бессмертие, отменяющее необходимость производства себе подобных иных и передачу им опыта. Нужно отметить, что природа уже испытала идею индивидуального бессмертия и отвергла ее как не соответствующую эволюционному успеху. Бесполое и вегетативное размножение, суть которого - производство точных копий родительского организма, - не что иное, как реализация модели индивидуального бессмертия. Однако наиболее успешные виды переходят к половому размножению, поскольку обеспеченное им разнообразие индивидуальных организмов и периодическая смена их другими, более приспособленными и обладающими новым качеством, приводит к эволюционному успеху, к развитию и совершенствованию. Молодое поколение через эволюционные функции адаптации и модернизации обеспечивает развитие (см.: Туринцева, Решетникова, 2015). Тогда как постчеловеческие технологические киборги, не имеющие необходимости не только производить потомство, но и собственные копии, теряют стимул к развитию.

Таким образом, трансгуманистический сценарий антропосоциальной эволюции, очевидно, вполне возможен. С точки зрения обсуждаемых проблем на первой стадии реализации такого сценария ставший почти совершенно искусственным мир включает в себя искусственное же, культивируемое общество. Оно не способно к саморегуляции в силу отсутствия необходимости взаимодействия между абсолютными и совершенными, бессмертными, а значит, не имеющими функций воспроизводства технологическими существами. Киборги, не способные к репродукции, по сути, лишаются смысла жизни, да и самой жизни, поскольку главное отличие живого от неживого заключается в возможности производства себе подобных. Вторая, она же последняя, стадия реализации трансгуманистического сценария - смерть одиноких и, строго говоря, уже мертвых технологических существ, их механическое разрушение.

Единственное, что, на наш взгляд, может остановить развитие антропосоциальной эволюции по этому пути, - глобальная катастрофа до того момента, когда производство искусственного интеллекта станет массовым и техника получит возможности самостоятельного воспроизводства. Наиболее вероятной выглядит война с применением уже существующего высокотехнологического оружия, способного уничтожить 
большую часть известного нам естественного и искусственного мира. В случае сохранения планеты от разрушения наверняка сохранятся и какие-то, возможно, и высшие формы жизни, в том числе человек. Однако технологические знания будут утеряны, технократическая цивилизация «обнулится», антропосоциальная эволюция начнется с начала. Аругая возможная катастрофа ассоциируется с факторами, также непосредственно связанными с выживанием отдельных людей или сохранением их интеллекта. Например, известно, что в тесном пространстве урбанизированной среды актуализируются биосоциальные механизмы регуляции численности, такие как нарушение репродуктивной функции, психические и аутоиммунные заболевания, появление и быстрое распространение высоколетальных инфекций, суицидальное или асоциальное поведение и др. Каждый из этих факторов при определенных условиях может привести к плачевным для технологической цивилизации последствиям.

\section{ЗАКАЮЧЕНИЕ}

В заключение хотелось бы сказать, что, несмотря на преобладание пессимистических прогнозов как в әтой статье, так и в многочисленных публикациях конца ХХ начала XXI в. на тему перспектив человечества, авторы глубоко уверены в реализации гуманистического сценария развития цивилизации. К тому есть предпосылки как теоретического, так и практического характера, как биологического (инстинкт самосохранения не только отдельных особей, но и вида в целом), так и социального плана. К последним мы относим осознание во всем мире ценностей взаимопомощи и коллективизма, и при этом ценности сохранения творческой свободы личности, становление гуманитарной экспертизы внедряемых технологий, новые технические возможности Аля коммуникации, новое отношение к здоровью и многое другое. Каждое устремление человека к самоуничтожению может быть уравновешено таким же стремлением остановиться у края пропасти и спастись. Тревожные явления в обществе вызывают потребность их осмысления и рождают решение сложных проблем еще до их возникновения. Так, Вал. А. Ауков считает, что те перемены в природе человека, которые могут быть им самим сконструированы и осуществлены, с одной стороны, вызывают обостренный интерес трансгуманистов и негативные сценарии антропосоциального развития, но с другой стороны, этот интерес и эти сценарии дают импульс для продуктивных дискуссий и формируют «ответ общества» в виде соответствующих правовых, организационных, экономических, социокультурных условий для положительных изменений в отношении реальных людей (Иуков, 2013а). Все эти аргументы позволяют нам надеяться на позитивный путь дальнейшей антропосоциальной эволюции.

\section{СПИСОК АИТЕРАТУРЫ}

Амосов, Н. М. (1979) Алгоритмы разума. Киев : Наукова думка. 221 с.

Ае Роберти, Е. В. (2008) Новая постановка вопросов социологии : избр. тр. СПб. : Алетейя. 496 c.

Иванов, Вяч. В. (2007) Избранные труды по семиотике и истории культуры : в 7 т. М. : Языки славянских культур. Т. 4. Знаковые системы культуры, искусства и науки. 792 с.

Ауков, Вал. А. (2011) Биосоциология // Знание. Понимание. Умение. № 3. С. 319-323.

Ауков, Вал. А. (2012а) Биосоциология молодежи и будущее гражданского общества // Знание. Понимание. Умение. № 1. С. 13-19.

Ауков, Вал. А. (2012b) Биосоциология молодежи: экспертные оценки изменений в обществе, связанных с увеличением продолжительности жизни // Знание. Понимание. Умение. № 4. C. $77-83$. 
Ауков, Вал. А. (2012c) Биосоциология молодежи: экспертные оценки изменений в новых поколениях // Знание. Понимание. Умение. № 3. С. 146-156.

Ауков, Вал. А. (2012d) Будущее молодежи в обществе будущего // Человек. № 4. С. 38-48.

Ауков, Вал. А. (2013а) Развитие человека в свете биосоциологии // Знание. Понимание. Умение. № 4. С. 25-33.

Ауков, Вал. А. (2013b) Биосоциология молодежи: теоретико-методологические основания. М. : ИзА-во Моск. гуманит. ун-та. 430 с.

Ауков, Вал. А. (2014) Биосоциология как теоретическая концепция // Гуманитарные ориентиры научного познания / отв. ред. П. А. Тищенко. М. : Навигатор. 352 с. С. 275-286.

Ауков, Вал. А. (2015) Биосоциология: ресурс понимания нового поколения России // Стратегические приоритеты. № 1 (5). С. 72-83.

Маслоу, А. Г. (1999) Аальние пределы человеческой психики : пер. с англ. СПб. : Евразия. 432 с.

Прайд, В. (2008) Увеличение продолжительности жизни: социальные изменения, прогнозы [Электронный ресурс] // Российское трансгуманистическое движение. URL: http://www.transhumanism-russia.ru/content/view/685/110/ (дата обращения: 24.12.2014).

Решетников, В. А. (2012) Повседневный антигуманизм и проблема онтологической безопасности // Казанская наука. № 5. С. 140-143.

Решетникова, Е. В. (2005) Сущность современного гуманизма и основные направления его социализации : дис. ... канд. филос. наук. Иркутск. 142 с.

Решетникова, Е. В. (2012) Конструктивный гуманизм как духовное основание социальной работы // Социальная работа и современность: теория и практика : материалы VII Междунар. науч.-практ. конф. / под ред. Б. В. Новикова, А. М. Аимитровой. Киев : Изд.-во НТУУ-КПИ. 356 c. C. $96-98$.

Решетникова, Е. В., Туринцева, Е. А. (2013) Социокультурные особенности семьи военнослужащего. Иркутск : Изд-во ИГУ. 139 с.

Степин, В. С. (2011) Цивилизация и культура. СПб. : ИзА-во СПбГУП. 408 с.

Тоффлер, Э. (2002) Шок будущего : пер. с англ. М. : АСТ. 557 с.

Туринцева, Е. А., Решетникова, Е. В. (2015) Биосоциальные функции молодежи и их трансформация в условиях городского образа жизни в контексте социальной реабилитации // Знание. Понимание. Умение. № 1. С. 134-143.

Туринцева, Е. А., Решетникова, Е. В., Гладкова, Т. В. (2015) Взаимопомощь в контексте русской культуры: социально-экологические и философские аспекты // Консолидация российского общества: организационные, образовательные и социокультурные ресурсы : материалы Всерос. науч.-практ. конф. / под ред. О. А. Кармадонова, О. А. Полюшкевича. Иркутск : Изд-во ИГУ. 374 с. С. $68-75$.

Федотова, В. Г. (2005) Хорошее общество. М. : Прогресс-Традиция. 544 с.

Фурсов, А. И. (2010) Колокола истории [Электронный ресурс] // Русский обозреватель. URL: www.rus-obr.ru/files/files/Bells-of-History.doc (дата обращения: 14.12.2015).

Epstein, J. M., Axtell, R. L. (1996) Growing Artificial Societies: Social Science from the Bottom Up. Brookings Institution Press. 224 p.

Sorokin, P. A. (1944) Russia and The United States. N. Y. : E. P. Dutton and Company, Inc. 253p.

Аата поступления: 22.02.2016 г.

\section{BIOSOCIAL MAN AND POSSIBLE DIRECTIONS OF ANTHROPOSOCIAL EVOLUTION}

\section{E. A. TURINTSEVA, E. V. RESHETNIKOVA}

(IRKUTSK STATE UNIVERSITY)

The article discusses the biosocial nature of human beings and associated prospects for the humanity. A theory of biosociology advanced by Val. A. Lukov puts it into an interdisciplinary perspective, where natural sciences and humanities drift toward each other, thus giving rise to a new theory of how the biological and the social co-exist in man. 
Our research has shown that if we see both the social and personal as a development of universal biological strategies common for the kingdom of animals (Animalia), then the factor specific for human evolution is to be found in parallel and balanced development of biological organisms (individuals) and a social community (society). The current directions of anthroposocial evolution may shift towards personality development person or towards the social imperative. In either case, the loss of balance will lead to the end of man and the catastrophe of mankind. It is only through preserving this equilibrium that humanity can survive and develop.

If we, however, understand the social as the 'non-biological', then the problem of biosocial man can be addressed from the perspective of differentiation between the natural and the man-made. In this case, the social can be linked to man's instrument-making capability, to the advancement of technology and the rise of technocratic civilization. Today the symbiosis between man and technology is capable of producing a new type of body. It is even easier to create a non-biological body from nanocomposite materials. Such a body will be devoid of many 'human' functions and the systems conditioned by them. Thus the future man will partly or completely lack the biological body which used to be man's constituent factor. Ensuing communal interaction between cyborgs as 'new people' is another question worth discussing. Having considered several versions of their future, we arrived at the conclusion that there is no alternative to setting up a 'cultivated' society for cyborgs.

Thus, in defining the biosocial in man as a correlation between the natural and the man-made, we can envision a gradual but irreversible transition from natural to man-made world, ultimately leaving no place for mankind and its sociality as we knew them.

Keywords: biosociology, anthroposocial evolution, human enhancement, humanism, transhumanism.

REFERENCES

Amosov, N. M. (1979) Algoritmy razuma [Algorithms of reason]. Kiev, Naukova dumka Publ. 221 p. (In Russ.).

De Roberti, E. V. (2008) Novaia postanovka voprosov sotsiologii : izbrannye trudy [A new take on the issues of sociology: Selected writings] St. Petersburg, Aleteiia Publ. 496 p. (In Russ.).

Ivanov, V. V. (2007) Izbrannye trudy po semiotike i istorii kul'tury [Selected works on semiotics and history of culture]: in 7 vols. Moscow, Iazyki slavianskikh kul'tur Publ. Vol. 4. Znakovye sistemy kul'tury, iskusstva i nauki [Sign systems in culture, art and science]. 792 p. (In Russ.).

Lukov, Val. A. (2011) Biosotsiologiia [Biosociology]. Znanie. Ponimanie. Umenie, no. 3, pp. 319-323. (In Russ.).

Lukov, Val. A. (2012a) Biosotsiologiia molodezhi i budushchee grazhdanskogo obshchestva [Biosociology of youth and the future of civil society]. Znanie. Ponimanie. Umenie, no. 1, pp. 13-19. (In Russ.).

Lukov, Val. A. (2012b) Biosotsiologiia molodezhi: ekspertnye otsenki izmenenii v obshchestve, sviazannykh s uvelicheniem prodolzhitel'nosti zhizni [Biosociology of youth: Expert evaluations of social changes connected with the increase of lifetime]. Znanie. Ponimanie. Umenie, no. 4, pp. 77-83. (In Russ.).

Lukov, Val. A. (2012c) Biosotsiologiia molodezhi: ekspertnye otsenki izmenenii v novykh pokoleniiakh [Biosociology of youth: Expert evaluations of change in new generations]. Znanie. Ponimanie. Umenie, no. 3, pp. 146-156. (In Russ.).

Lukov, Val. A. (2012d) Budushchee molodezhi v obshchestve budushchego [The future of youth in the society of the future]. Chelovek, no. 4, pp. 38-48. (In Russ.).

Lukov, Val. A. (2013a) Razvitie cheloveka v svete biosotsiologii [Human development in the light of biosociology]. Znanie. Ponimanie. Umenie, no. 4, pp. 25-33. (In Russ.)

Lukov, Val. A. (2013b) Biosotsiologiia molodezhi: teoretiko-metodologicheskie osnovaniia [Biosociology of youth: theoretical and methodological foundations]. Moscow, Moscow University for the Humanities Publ. 430 p. (In Russ.).

Lukov, Val. A. (2014) Biosotsiologiia kak teoreticheskaia kontseptsiia [Biosociology as a theoretical concept]. In: Gumanitarnye orientiry nauchnogo poznaniia [Humanitarian landmarks of scientific cognition]/ ed. by P. D. Tishchenko. Moscow, Navigator Publ. 352 p. Pp. 275-286. (In Russ.). 
Lukov, Val. A. (2015) Biosotsiologiia: resurs ponimaniia novogo pokoleniia Rossii [Biosociology: A resource to understand Russia's new generation]. Strategicheskie prioritety, no. 1 (5), pp. 72-83. (In Russ.).

Maslow, A. H. (1999) Dal'nie predely chelovecheskoi psikbiki [The Farther Reaches of Human Nature]. St. Petersburg, Evraziia Publ. 432 p. (In Russ.).

Praid, V. (2008) Uvelichenie prodolzhitel'nosti zhizni: sotsial'nye izmeneniia, prognozy [Extending human lifespan: social change and forecasts]. Rossiiskoe transgumanisticheskoe dvizhenie [online] Available at: http://www.transhumanism-russia.ru/content/view/685/110/ (accessed on: 24.12.2014). (In Russ.).

Reshetnikov, V. A. (2012) Povsednevnyi antigumanizm i problema ontologicheskoi bezopasnosti [Antihumanism in everyday life and the issue of ontological security]. Kazanskaia nauka, no. 5, pp. 140-143. (In Russ.).

Reshetnikova, E. V. (2005) Sushchnost' sovremennogo gumanizma i osnovnye napravleniia ego sotsializatsii [The essence of contemporary humanism and the main directions of its socialization]: Thesis... Candidate of Philosophy. Irkutsk. 142 p. (In Russ.).

Reshetnikova, E. V. (2012) Konstruktivnyi gumanizm kak dukhovnoe osnovanie sotsial'noi raboty [Constructive humanism as a moral foundation of social work]. In: Sotsial'naia rabota $i$ sovremennost': teoriia i praktika : materialy VII Mezbdunar. nauch.-prakt. konf. [Social work and modernity: Theory and practice: Proceedings of $8^{\text {th }}$ International conference]/ ed. by B. V. Novikov and L. M. Dimitrova. Kiev, NTUU-KPI Publ. 356 p. Pp. 96-98. (In Russ.).

Reshetnikova, E. V. and Turintseva, E. A. (2013) Sotsiokul'turnye osobennosti sem'i voennosluzhashchego [Sociocultural specifics of families in the military forces]. Irkutsk, Irkutsk State University Publ. 139 p. (In Russ.).

Stepin, V. S. (2011) Tsivilizatsiia i kul'tura [Civilization and culture]. St. Petersburg, SPbGUP Publ. 408 p. (In Russ.).

Toffler, A. (2002) Shok budusbchego [The future shock]. Moscow, AST Publ. 557 p. (In Russ.).

Turintseva, E. A. and Reshetnikova, E. V. (2015) Biosotsial'nye funktsii molodezhi i ikh transformatsiia v usloviiakh gorodskogo obraza zhizni v kontekste sotsial'noi reabilitatsii [Biosocial Functions of the Youth and Their Transformations in the Context of Social Rehabilitation in Urban Mode of Life]. Znanie. Ponimanie. Umenie, no. 1, pp. 134-143. (In Russ.).

Turintseva, E. A., Reshetnikova, E. V. and Gladkova, T. V. (2015) Vzaimopomoshch' v kontekste russkoi kul'tury: sotsial'no-ekologicheskie i filosofskie aspekty [Mutual aid in the context of Russian culture: socio-environmental and philosophical aspects]. In: Konsolidatsiia rossiiskogo obshchestva: organizatsionnye, obrazovatel'nye i sotsiokul'turnye resursy : materialy Vseros. nauch.-prakt. konf. [Consolidating the Russian society: Organizational, educational and sociocultural resources: Proceedings of All-Russia conference]/ ed. by O. A. Karmadonov, O. A. Poliushkevich. Irkutsk, Irkutsk State University Publ. 374 p. Pp. 68-75. (In Russ.).

Fedotova, V. G. (2005) Khoroshee obshchestvo [A good society]. Moscow, Progress-Traditsiia Publ. 544 p. (In Russ.).

Fursov, A. I. (2010) Kolokola istorii [Bells of history]. Russkii obozrevatel' [online]Available at: http://www.rus-obr.ru/files/files/Bells-of-History.doc (accessed on: 14.12.2015). (In Russ.).

Epstein, J. M. and Axtell, R. L. (1996) Growing Artificial Societies: Social Science from the Bottom Up. Brookings Institution Press. 224 p.

Sorokin, P. A. (1944) Russia and The United States. N. Y. : E. P. Dutton and Company, Inc. 253 p.

Submission date: 22.02.2016.

Туринцева Елена Анатольевна - кандидат социологических наук, доцент кафедры социальной работы Иркутского государственного университета. Адрес: 664009, Россия, г. Иркутск, ул. Карла Маркса, А. 1, к. 302. Тел.: +7 (3952) 200-205; +7 (3952) 243-372. Эл. адрес: e_turin05 @mail.ru 
Решетникова Екатерина Владимировна - кандидат философских наук, заведующий кафедрой социальной работы Иркутского государственного университета. Адрес: 664009, Россия, г. Иркутск, ул. Карла Маркса, А. 1, к. 302. Тел.: +7 (3952) 200-205; +7 (3952) 243-372. Эл. адрес: eresh80@mail.ru

Turintseva Elena Anatolievna, Candidate of Sociology, Associate professor, Department of Social Work, Institute of Social Sciences, Irkutsk State University. Postal address: Room 302, 1 Karl Marx St. 664009, Irkutsk, Russian Federation. Tel.: +7 (3952) 200-205, +7 (3952) 243-372. E-mail: e_turin05@mail.ru

Reshetnikova Ekaterina Vladimirovna, Candidate of Philosophy, Associate Professor and Chair, Department of Social Work, Institute of Social Sciences, Irkutsk State University. Postal address: Room 302, 1 Karl Marx St. 664009, Irkutsk, Russian Federation. Tel.: +7 (3952) 200-205, +7 (3952) 243-372. E-mail: eresh80@mail.ru 